\title{
Estudo de estrutura eletrônica da interação de inibidores da proteína Tirosina Quinase Abl-Bcr na forma mutada frente a forma selvagem.
}

\author{
*Washington A. Pereira ${ }^{1}$ (PG), Érica C. M. Nascimento ${ }^{2}$ (PQ), João B. L. Martins ${ }^{1}$ (PQ). \\ was.a.pra@gmail.com \\ ${ }^{1}$ Universidade de Brasília, Laboratório de Química computacional, IQ, CP 4478, Brasília-DF, Brasil. \\ ${ }^{2}$ Departamento de Quí mica Fí sica y Analítica, Universitat Jaume I, Castellón, Espanha.
}

\section{RESUMO}

As proteínas quinases constituem uma das maiores famílias de proteínas nos eucariotos e são as principais responsáveis por meios de comunicação intracelular, resultando no controle celular e na regulação dos sinais de transdução[1]. $O$ mecanismo regulador das quinases inclui vários fenômenos, que abrange desde propriedades químicas e estruturais até o controle transcricional[2]. Devido a sua atividade, as quinases são proteínas que estão envolvidas na origem de várias doenças, entre elas a Leucemia e seus subtipos. Os estudos de estrutura eletrônica da tirosina quinase Bcr-Abl e de quatro fármacos inibidores desta proteína, com métodos ONIOM e Dinâmica Molecular, podem auxiliar para uma melhor compreensão do mecanismo de ação desta proteína[3]. Essas ferramentas computacionais têm se mostrado úteis para o estudo de sistemas macromoleculares como proteínas e ligantes, sendo possível comparar as diferentes mutações e diferentes inibidores, além de apontar características inibitórias para uma eficiente inibição dos alvos biológicos[4]. Neste trabalho serão apresentados alguns aspectos da interação do inibidor da tirosina quinase Bcr-Abl com o fármaco.

Palavras-chave: Tirosina Quinase, Inibidores, estrutura eletrônica, ONIOM, DFT

A leucemia mieloide crônica (LMC) é um tipo de câncer não hereditário que se desenvolve na medula óssea com ocorrência mais frequente em adultos na faixa etária dos 50 anos (apenas $4 \%$ dos pacientes são crianças). A LMC se distingue dos outros tipos de leucemia pela presença de uma anormalidade genética nos glóbulos brancos, denominada cromossomo Philadelphia $(\mathrm{Ph}+)$. Estudos mostraram que, em pacientes portadores de LMC, existe uma translocação (fusão de uma parte de um cromossomo em outro cromossomo) entre os cromossomos 9 e 22, caracterizando assim a leucemia mieloide crônica[5].

O tratamento da doença na fase crônica é feito por fármacos denominados de inibidores da tirosina quinase (TKI). Esses inibidores se ligam ao sítio ativo da proteína, bloqueando o acesso do substrato natural ao sítio catalítico da proteína, impedindo a fosforização da tirosina quinase. Entretanto, devido ao grande número de mutações possíveis no sítio da proteína, esses inibidores quase sempre perdem seu poder inibitório e a doença avança de fase[6].

Uma das dificuldades em se trabalhar com sistemas biológicos é o grande número de átomos e variáveis envolvidas no problema. Mesmo com o avanço da capacidade computacional, estudos de estrutura eletrônica mais acurados têm elevado custo computacional. Uma alternativa a ser considerada é o uso de métodos híbridos como o $Q M / M M$. Nesta metodologia o sistema pode ser dividido em diferentes partes (camadas). Ao dividirmos o sistema receptor-ligante em camadas, podemos tratar cada uma destas camadas com diferentes níveis de cálculos com maior ou menor rigor computacional[7].

O procedimento utilizado foi escolher as proteínas no banco de dados de estruturas, Protein Data Bank (PDB), para busca sobre o os principais fármacos. Foi utilizado o programa docking Auto Docking Vina, para mapear os aminoácidos que participam direta ou indiretamente do processo inibitório e também determinar qual tipo de interação que cada resíduo faz com a proteína. Aplicando o método ONIOM (camada alta usando método PM6 e na camada baixa AMBER), foram determinadas a energia de interação entre os aminoácidos o inibidor. Buscando uma maior precisão a partir do ligante e uma mutação em específico (T315I) o número de aminoácidos presentes na camada alta (nível de cálculo PM6) foi sendo ampliado até atingir a região da proteína onde esperado que, os aminoácidos dessa região não tenham participação significativa no processo de interação . 


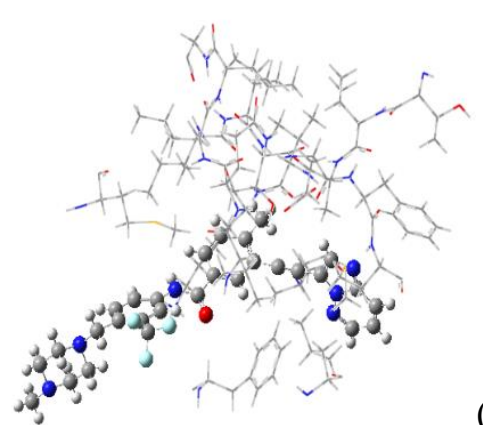

(a)

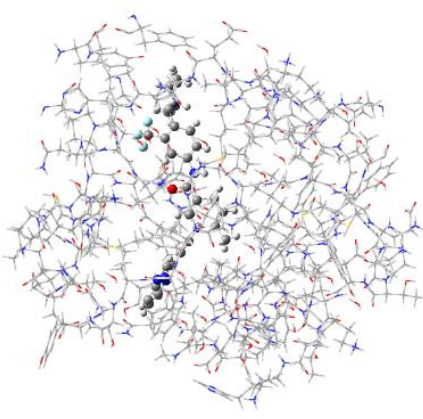

(b)

Figura 1. Representação do sistema proteína-ligante estudado. ONIOM: (a) Complexo tirosina quinase-Ponatinibe, considerando distância de 4 Å. (b) Complexa tirosina quinase Ponatinibe, considerando distância de $12 \AA$

Os cálculos foram realizados com o software Gaussian09, utilizando a ferramenta Tao Toolkit e Ambertools. O campo de força escolhido para o cálculo foi o AMBER. Os ligantes estão sendo submetidos ao método DFT B3LYP.

O método ONIOM tem se mostrado um método adequado para tratar sistemas biológicos, tornado o custo computacional e tempo para cálculos adequados e possibilitando trabalhar as regiões das proteínas mais importantes, com métodos mais sofisticados e de custo computacional maior, com maior precisão e demais áreas com métodos com menor rigor computacional. As diferentes técnicas estão fornecendo resultados importantes, para analisar de forma mais profunda a proteína e seus ligantes.

\section{Referencias.}

[1] Lopes, Nei R., and M. T. Abreu. Inibidores de tirosino quinase na leucemia mielóide crônica. Rev Bras Hematol Hemoter, 31 (2009) 449-53.

[2] Silva, Bárbara V., et al. Proteínas quinases: características estruturais e inibidores químicos. Quim. Nova, 32 (2009) 453-462.

[3] Buchdunger, Elisabeth, et al. Abl protein-tyrosine kinase inhibitor STI571 inhibits in vitro signal transduction mediated by c-kit and platelet-derived growth factor receptors. J. Pharm. Exp. Therap. 295 (2000) 139-145.

[4] Lugo, Tracy G., et al. Tyrosine kinase activity and transformation potency of bcr-abl oncogene products. Science, 247 (1990) 1079-1082.

[5] Capece, Luciana, et al. Complete reaction mechanism of indoleamine 2, 3-dioxygenase as revealed by QM/MM simulations. J. Phys. Chem. B, 116 (2012) 1401-1413.

[6] Dittrich, B.; Pfitzenreuter, S.; Hübschle, C. B. On QM/MM and MO/MO cluster calculations of all-atom anisotropic displacement parameters for molecules in crystal structures. Acta Crystall. A: 68 (2012) 110-116,.

[7] Vreven, Thom, and Keiji Morokuma. Hybrid methods: Oniom (qm: mm) and qm/mm. Annual Rep. Comp. Chem. 2 (2006): $35-51$. 